\title{
Study of Primary Infertility in females by Diagnostic Laparoscopy
}

\author{
Dr. Preeti Kanal MS and Dr. Sanjaya Sharma MD \\ Department of Obstetrics \& Gynecology, M L B Medical College, Jhansi (UP), India
}

(Received 12 December 2005 and accepted 03 February 2006)

\begin{abstract}
Infertility has become nowadays not only a medical, but a social problem as well. The study was conducted on 40 patients of primary infertility over a period of one year from January 2001 to December 2002. The aim was to evaluate causes of infertility by diagnostic laparoscopy. The average age of women was 26.8 years. About half of the patients were brought to hospital within 6 years of infertility. Tubal block was one of the major causes of primary infertility. The diagnostic laparoscopy with hysterosalpingography (HSG) can be helpful to diagnose the tubal pathology.
\end{abstract}

KEY WORDS: Primary infertility, Diagnostic laparoscopy, hysterosalpingography, Tubal block.

\section{INTRODUCTION:}

Primary infertility is defined as inability of a couple to achieve pregnancy within one year of defined time of unprotected intercourse with adequate coitus. The incidence of infertility in any community varies between $5 \%$ and $15 \%$. Both partners in relationship contribute to potential fertility and both may be sub fertile. The female factors contribute most (i.e. 40-55\%) in the etiologies of infertility followed by male factors (30-40\%), both partners (10\%) and unexplained $(10 \%){ }^{1}$ Infertility in female is caused by various factors. To determine the causes of sterility or impaired fertility, one must visualize the process of reproduction from gametogenesis to nidation.

Diagnostic laparoscopy provides a direct visual access to inner pelvic anatomy without restoring to major abdominal surgery so that physiology of the ovaries, fallopian tubes \& uterus can now be studied in more details. Our aim of study is to find out the causes of infertility in otherwise tested normal women, to evaluate tubal morphology \& patency by dye testing so as to avoid unnecessary laparotomy.

\section{MATERIALS AND METHODS:}

The patients of the age group 20-40 years were selected from gynecology out patients department and admitted in inpatients department of obstetrics \& gynecology of M L B Medical College and Hospital Jhansi (UP), India. The study was conducted from January 2001 to December 2002. The females were selected who could not achieve pregnancy within one year of defined time of unprotected intercourse with adequate coitus.

Initially, the infertile couples were examined by taking detailed history, physical examination, basic endocrinological investigations and semen analysis. After that, general examination, systemic examination and local genital examination were carried out on the patients selected for this study.

Diagnostic laparoscopy was performed in post menstrual phase under general anesthesia. All the patients undergoing this procedure were investigated properly for full blood count, blood urea, blood sugar, urine examination, ECG, chest x-ray, husband's seminogram, basal body temperature, luteinizing hormone monitoring, endometrial biopsy and ultrasonography. The chromotubation was carried out in all cases of infertility to test the patency of tubes under laparoscopic vision by using $10-15 \mathrm{ml}$ of $0.5 \%$ autoclaved methylene blue dye. All the cases under the study went for HSG first and after HSG they went for laparoscopy.

Corresponding Address: Dr. (Mrs.) Preeti Kanal, Senior Resident, Department of Obstetrics \& Gynecology, M L B Medical College, Jhansi (UP), India Email: preeti_dr@rediffmail.com 


\section{RESULTS:}

The present study showed maximum cases of infertility (45\%) in the age group of $21-25$ years followed by $35 \%$ cases of infertility in the age group of 26-30 years (Table 1). As per the period of infertility after marriage is concerned, majority of cases (18 out of 40 cases) were brought to hospital within 1-5 years of infertility (Table 2). On laparoscopy, twenty eight out of 40 patients (70\%) revealed abnormal findings and rest had normal pelvic findings. The tubal blockage without adhesions was found to be most important abnormality and was seen in $22.5 \%$ cases followed by tubal blockage with adhesions (15\%). Out of 17 cases of tubal blocks, bilateral tubal block was found in 13 cases of primary infertility (Table 3). Laparoscopy with HSG (Hysterosalpingography) revealed 20 cases of tubal blockage (16 bilateral and 4 unilateral) as compared to laparoscopy alone, which showed 17 cases of tubal blockage (13 bilateral and 4 unilateral) (Table 4).

Table 1: Distribution of cases of primary infertility according to age

\begin{tabular}{cccc}
\hline S.N. & Age in Years & Number of Cases & $\mathbf{\%}$ \\
1. & $21-25$ & 18 & 45 \\
2. & $26-30$ & 14 & 35 \\
3. & $31-35$ & 8 & 20 \\
\hline
\end{tabular}

Table 2: Distribution of cases according to duration of infertility

\begin{tabular}{cccc}
\hline S.N. & Duration of infertility (yrs) & No. of Cases & \% \\
1 & $1-5$ & 18 & 45 \\
2 & $6-10$ & 14 & 35 \\
3 & $11-15$ & 5 & 12.5 \\
4 & $16-20$ & 3 & 7.5 \\
\hline
\end{tabular}

Table 3: Laparoscopic findings

\begin{tabular}{cccc}
\hline S.N. & Findings & No. of Cases & $\mathbf{\%}$ \\
$\mathbf{1 .}$ & Normal pelvic organs & 12 & 30 \\
$\mathbf{2 .}$ & Tubal block with adhesions & 6 & 15 \\
$\mathbf{3 .}$ & Tubal block without adhesions & 9 & 22.5 \\
$\mathbf{4 .}$ & Tubal block with cystic ovaries & 2 & 5 \\
$\mathbf{5 .}$ & Tubal Patency with cystic ovary & 2 & 5 \\
$\mathbf{6 .}$ & Tubal patency with adhesions & 3 & 7.5 \\
$\mathbf{7 .}$ & Genital tract tuberculosis & 2 & 5 \\
$\mathbf{8 .}$ & Endometriosis with uterine fibromyoma & 2 & 5 \\
$\mathbf{9 .}$ & Hypoplastic uterus & 2 & 5 \\
\hline
\end{tabular}

Table 4: Comparison of tubal block by Laparoscopy HSG \& Laparoscopy

\begin{tabular}{ccccc}
\hline Tubal patency & Laparoscopy with HSG & \% & Laparoscopy alone & \% \\
Both tubes patent & 20 & $50 \%$ & 23 & $57.5 \%$ \\
Unilateral block & 4 & $10 \%$ & 4 & $10 \%$ \\
Bilateral block & 16 & $40 \%$ & 13 & $32.5 \%$ \\
\hline
\end{tabular}

\section{DISCUSSION:}

Tubal factor, which accounts for $15-30 \%$ of infertility in all women, is common in developing countries with high rates of pelvic inflammatory disease but limited resources ${ }^{2}$. The present study shows abnormal pelvic findings in $70 \%$ cases of primary infertility. The mean age of women is 26.8 years. This is consistent with the observation of Jedrzejczak P $\mathbf{e l ~} \mathbf{~ a l}^{3}$, who found mean age of primary infertility 28.5 years. Maximum number of patients (46.67\%) presented with less than 6 years of infertility. Tubal blockage was found to be the most common cause of infertility i.e. $42.5 \%$ followed by pelvic adhesions. Cystic ovaries, endometriosis, uterine myoma, genital 
tuberculosis and hypo-plastic uterus were also seen. These findings were similar to the study conducted in Thailand by Sinawat $\mathrm{S}$ et $\mathbf{a l}^{4}$. Laparoscopy combined with Hysterosalpingography (HSG) is more effective method to reveal tubal blocks. However recent studies $^{5,}$ 6, 7, 8 shows, that hysterosalpingocantrast sonography (HyCoSy) is a cost effective screening test as compared to diagnostic laparoscopy with HSG in the assessment of tubal patency for the investigations of infertility patients.

\section{CONCLUSION:}

Tubal abnormalities are detected in about half of the infertile females brought to hospital for treatment. Laparoscopy along with HSG is very effective method in evaluating cases of primary infertility especially tubal blockage. Further studies are needed to investigate the etiologies of these abnormalities at the earliest; this could be a measure to bring down the occurrence of such conditions.

It should be appreciated that HSG and Laparoscopy are complimentary rather that competitive procedures. The accuracy of diagnosis is enhanced when two procedures are combined especially in those cases where the result of one of the tests is doubtful. In the days of modern gynecology, salpingoscopy and falloscopy via hysteroscope are the alternatives available for assessment of tubal patency.

\section{REFERENCES:}

1. Padubidri VG and Daftary Shirish N. The Pathology of conception. Shaw's Text book of Gynaecology 12th edition. BI Churchill Livingstone, New Delhi 1983: 154-68.

2. Hoffman L, Chan K, Smrth B, Okolo S. The value of saline salpingosonography as a surrogate test of tubal patency in lowresource setting. Int J Fertil Womens Med. 2005 May-Jun;50(3):135-9.

3. Jedrzejczak P, Luczak-Wawrzyniak J, Szyfter J, Przewozna J, Taszarek-Hauke G, Pawelezyk L. Feeling and emotions treated for infertility. Przegl Lek. 2004;61(12):1334-7.

4. Sinawat S, Pattamadilok J, Seejorn K. Tubal abnormalities in Thai infertile females. J Med Assoc Thai. 2005 Jun;88(6):723-7.

5. Shahid N, Ahluwalia A, Briggs S, Gupta S. An audit of patients investigated by Hysterosalpingo-Contrast-Sonography (HyCoSy) for infertility. J Obstet Gynaecol. 2005 Apr;25(3):275-8.

6. Exacoustos C, Zupi E, Carosotti C, Lanzi G, Marconi D, Arduini D. HysterosalpingoContrast Sonography compared with hysterosalpingography and Laparoscopic dye perturbation to evaluate tubal patency. $J$ Am Assoc Gynecol Laparosc. 2003 Aug;(10):367-72.

7. Chan CC, Ng EH, Tang OS, Chan KK, Ho PC. Comparison of three-dimensional hysterosalpingo-contrast-sonography and diagnostic laparoscopy with chromopertubation in the assessment of tubal patency for the investigation of subfertility. Acta Obstet Gynecol Scand. 2005 Sep;84(9):909-13.

8. Ayida G, Chamberlain P, Barlow D, Koninckx P, Golding S, Kennedy S. Is routine diagnostic laparoscopy for infertility still justified? A pilot study assessing the use of hysterosalpingo-contrast sonography and magnetic resonance imaging. Human Reproduction. 1997 Jul;12(7):1436-9. 